\title{
HACIA EL RECONOCIMIENTO DE LA INCLUSIÓN DIGITAL COMO UN DERECHO FUNDAMENTAL EN COLOMBIA*
}

\author{
TOWARDS THE RECOGNITION \\ OF DIGITAL INCLUSION AS A \\ FUNDAMENTAL RIGHT IN COLOMBIA
}

\author{
Ángela María Chacón-Penagos** \\ José Armando Ordóñez-Córdoba*** \\ Angélica María Anichiarico-González ${ }^{* * * *}$ \\ Fecha de recepción: 2 de junio de 2016 \\ Fecha de aceptación: 4 de septiembre de 2016 \\ Disponible en línea: 30 de mayo de 2017
}

\section{Para citar este artículo/To cite this article}

Chacón-Penagos, Ángela María; Ordóñez-Córdoba, José Armando \& Anichiarico-González, Angélica María, Hacia el reconocimiento de la inclusión digital como un derecho fundamental en Colombia, 134 Vniversitas, 139-168 (2017). http://dx.doi.org/10.11144/Javeriana.vj134.hrid

doi:10.11144/Javeriana.vj134.hrid

* Este artículo de revisión es producto de la ejecución del proyecto La inclusión digital en el marco de los derechos fundamentales, adscrito al Grupo de Investigación Interdisciplinaria en Ciencias Sociales y Humanas GIICSH de la Corporación Universitaria Autónoma del Cauca.

** Abogada, Universidad del Cauca. Especialista en derecho penal, Universidad Libre de Cali. Investigadora, Corporación Universitaria Autónoma del Cauca. Contacto: angela.chacon.p@uniautonoma. edu.co, amchacon.p@gmail.com

*** Ingeniero, Universidad del Cauca. Magíster en ingeniería y doctor en telemática. Coordinador de investigaciones de ingeniería, Fundación Universitaria de Popayán. Contacto: jaordonez@unicauca. edu.co

**** Abogada. Magíster en derechos humanos por la Universidad Carlos III de Madrid. Doctoranda en estudios avanzados en derechos humanos, Universidad Carlos III de Madrid y docente investigadora, Corporación Universitaria Autónoma del Cauca. Contacto: angie9276@gmail.com 


\section{RESUMEN}

Este artículo aborda el reconocimiento de la inclusión digital como derecho fundamental en Colombia, para contribuir al desarrollo de la teoría constitucional sobre reconocimiento de derechos fundamentales en nuestro país. En los últimos años, ha habido una importante actividad de la comunidad nacional e internacional con respecto a la brecha digital como problemática intrínsecamente asociada con los derechos fundamentales, al considerar que la inclusión digital es un motor de desarrollo preponderante para individuos y Estados. En el artículo se realiza una evaluación de la doctrina y los criterios jurisprudenciales acerca de la incorporación de nuevos derechos fundamentales y la protección por medio de la acción de tutela, mediante una revisión documental y hermenéutica jurídica, para explorar algunos argumentos que permiten justificar el reconocimiento de la inclusión digital como derecho fundamental en el ordenamiento jurídico colombiano.

Palabras clave: Inclusión digital; brecha digital; derechos fundamentales; acción de tutela 


\section{ABSTRACT}

This paper addresses the recognition of digital inclusion as a fundamental right in Colombia, thus contributing to the progress of the constitutional theory about the recognition of fundamental rights in Colombia. In recent years, the digital divide has attracted widespread attention of the national and international community. This digital divide has been intrinsically associated with the concept of fundamental right, since digital inclusion is considered as a key factor in social and individual progress. In this paper we conduct the evaluation of the doctrine and the case law criteria on the inclusion of new fundamental rights and the protection using the action for protection (tutela). This evaluation is carried out through a document review and legal interpretation that allows identifying some arguments to justify the consideration of digital inclusion as an inclusion to fundamental rights in the Colombian legal system.

Keywords: digital inclusion; digital divide; fundamental rights; action for protection (tutela)

\section{SUMARIO}

INTRODUCCIÓN.- I. BReChA DigitAl E INCLUSIÓN DigitAL.- II. ¿¿NuEVOS DERECHOS, NUEVAS GENERACIONES?- III. UNA APROXIMACIÓN COMO DERECHO Fundamental de la inclusión digital en Colombia.- IV. ACción de TUTELA COMO MECANISMO PARA LA PROTECCIÓN DE LA INCLUSIÓN DIGITAL.Conclusiones.- Bibliografía. 


\section{INTRODUCCIÓN}

Las tecnologías de la información y las comunicaciones (en adelante, TIC) pasaron de ser un progreso científico en un campo específico, a convertirse en una revolución de la vida humana, que afecta desde la comunicación cotidiana hasta tareas de alta complejidad relacionadas con la salud, la educación, la política y la economía. Las principales vertientes teóricas retratan el impacto de las TIC en la sociedad con dos conceptos: i) la sociedad de la información, que resalta cómo se genera y se conecta la información de las actividades humanas, del sistema económico y de la esfera cultural; y ii) la sociedad del conocimiento, que a diferencia de la anterior, se ocupa principalmente de cómo se usa esta información para tomar decisiones que abarcan dimensiones sociales, éticas y políticas mayores ${ }^{1}$.

A pesar de las grandes bondades que prometen estas sociedades, también presentan grandes retos. Uno, quizás el más importante de ellos, es la brecha digital, porque contradice la naturaleza de esta nueva sociedad, que aspira a extenderse con el objetivo de que todos podamos estar conectados produciendo y recibiendo información en igualdad de condiciones.

En este escenario, los individuos tenemos derecho a la inclusión digital, es decir, a integrarnos a estas nuevas sociedades para aprovechar las ventajas of recidas por ellas, por lo cual resulta perentorio encontrar soluciones efectivas al fenómeno de la brecha digital. En este sentido, mediante un estudio propio de derecho constitucional, se contribuirá con un análisis sobre la consagración de la inclusión digital como derecho fundamental con el fin de garantizar su efectividad. Para ello, se abordarán en primer lugar los conceptos de brecha digital, inclusión digital y se estudiará la relación entre inclusión digital y los derechos fundamentales. Posteriormente, se realizará una reflexión sobre la incorporación de nuevos derechos fundamentales y se indagará por la calidad de derecho fundamental que ostenta la inclusión digital desde el punto de vista doctrinal y en la realidad de algunos Estados en particular. Finalmente,

1 Patricia Martínez-Coral, Intervenciones públicas de inclusión digital: una aproximación a las dimensiones sociales y politicas de la conectividad, 19 Papel Politico, 1, 61-76 (2014). Disponible en: http://www.scielo.org.co/pdf/papel/v19n1/v19n1a04.pdf 
abriremos el debate acerca de los criterios de la jurisprudencia constitucional colombiana que permiten identificar la inclusión digital como derecho fundamental y el ejercicio de la acción de tutela para garantizarla.

\section{BRECHA DIGITAL E INCLUSIÓN DIGITAL}

Para Sergio Fernández-Riquelme², la revolución tecnológica conlleva la transformación de las formas de existencia y, usando el lenguaje de Ernst Forsthoff, la de los espacios vitales, al tiempo que aparecen nuevas manifestaciones de menesterosidad social que reclaman nuevas formas de actuación política y social. Al respecto, Forsthoff $\mathrm{f}^{3}$ explica que una existencia digna requiere que la persona tenga garantizado "el espacio vital", diferenciando entre espacio vital dominado y el espacio vital efectivo. El primero es definido como aquel segmento del espacio vital que la persona es capaz de proveer por sus propios medios (autodotarse), mientras que el espacio vital efectivo es aquel en que no está en las manos de la persona la consecución de su totalidad. Ante la imposibilidad de satisfacerse, aparece una menesterosidad social, es decir, aquella situación general de los ciudadanos que necesitan proveerse de los bienes indispensables para vivir dignamente. Así, el llamado a remediar esta precariedad es el Estado, el cual debe brindar las prestaciones en favor de las necesidades sociales insatisfechas ${ }^{4}$.

Esta procura a cargo del Estado, incluye para Manuel GarcíaPelayo, el desarrollo de sistemas o el control de sistemas necesarios para el desarrollo de la vida humana en la actual civilización, lo que incluye entre otras medidas, el progresivo acceso a los bienes culturales, con especial atención a la innovación y la posesión de los conocimientos tecnológicos.

2 Sergio Fernández-Riquelme, La realidad comunitaria de la política social: desafíos teóricos y metodológicos para el trabajo social, 47 Documentos de Trabajo Social: Revista de Trabajo Social y Acción Social, 31-42 (2010). Disponible en: http://www.trabajosocialmalaga.org/archivos/revista_dts_numeros/DTS_47.pdf

3 ERNST Forsthoff, El Estado de la sociedad industrial (Instituto de Estudios Políticos, Madrid, 1975). Disponible en: https://www.academia.edu/8664103/ERNST_FORSTHOFF_EL_ESTADO_SOCIEDAD_INDUSTRIAL

4 Wolfgang Abendroth, Ernst Forsthoff \& Karl Doehring, El Estado social, 80-88 (José PuenteEGIDO, trad., Centro de Estudios Constitucionales, Madrid, 1986).

5 Manuel García-Pelayo, Las transformaciones del Estado contemporáneo, 26-30 (Alianza, Madrid, 1985). 
Aquellos ciudadanos cuyo acceso a la innovación y a la tecnología hace parte de su espacio vital efectivo pero no tienen los medios suficientes para ello, padecen de lo que conocemos como brecha digital. La brecha digital es una exclusión sufrida por un grupo social, originada en disparidades socioeconómicas. Aunque la brecha digital tiene su origen en desigualdades preexistentes, esta brecha también refuerza y profundiza aún más esta desigualdad. Todos los provechos que conllevan las TIC y aquellas ventajas que aparecen con las sociedades de la información y el conocimiento, ofrecían la posibilidad de superar obstáculos existentes que sufrían los individuos de distintos sectores sociales; sin embargo, la brecha digital no solo derribó las esperanzas que traían estas nuevas sociedades, sino que también profundizó las barreras que ya existían entre las capas sociales?

Hay diversas definiciones de brecha digital, que puede entenderse como "la desigualdad entre los que tienen un ordenador y los que no lo tienen" o bien como "la disparidad entre los que tienen y los que no tienen internet" 9 . En el presente artículo, la brecha digital se asume como la desigualdad entre aquellos que tienen acceso a las TIC y aquellos que no, o que teniendo acceso, están en desventaja, por infraestructura, capacitación y/o equipamiento.

Hay distintas "clases" de brechas ${ }^{10}$ : i) la brecha global entre países, ii) la brecha social entre pobres y ricos de cada nación, $\mathrm{y}$ iii) la brecha democrática. Infortunadamente, en las tres brechas, Latinoamérica presenta desventajas pues las desigualdades en desarrollo industrial repercuten en las desigualdades de infraestructura

6 María del Carmen Agustín-Lacruz \& Manuel Clavero-Galofré, Indicadores sociales de inclusión digital: brecha y participación ciudadana, en Derecho, gobernanza y tecnologías de la información en la sociedad del conocimiento, 143-166 (Prensas Universitarias de Zaragoza, Zaragoza, 2010). Disponible en: http://eprints.rclis.org/14264/1/Indicadores_brecha.pdf

7 Pippa Norris, The Worldwide Digital Divide: Information Poverty, the Internet and Development, Paper for the Annual Meeting of the Political Studies Association of the UK, London School of Economics and Political Science, 10-13 th April 2000, 1-10 (2000). Disponible en: https://pdfs. semanticscholar.org/acff/d927594b58b81f18ec9f27c64ff9b2ad452e.pdf

8 National Telecommunications and Information Administration, Falling through the Net: Defining the Digital Divide [https:/www.ntia.doc.gov/report/1999/falling-through-net-defining-digital-divide], citada por Fernando Ballestero-Díaz, La brecha digital. El riesgo de exclusión en la sociedad de la información, 70-103 (Fundación Retevisión, Madrid, 2002).

9 Manuel Castells, La galaxia internet, 275 (Areté, Madrid, 2001).

10 Pippa Norris, Digital Divide: Civic Engagement, Information Poverty, and the Internet Worldwide, 305 (Cambridge University Press, Cambridge, UK, 2001). 
que en últimas es el motor de difusión de las $\mathrm{TIC}^{11}$. Por lo anterior, si los países periféricos no realizan una apuesta importante por la superación de la brecha digital se estaría condenando tanto a los individuos como a las naciones a un rezago insuperable en todos los campos ${ }^{12}$.

En este contexto emerge el concepto de inclusión digital, como una forma de inserción social imprescindible para el crecimiento de cualquier comunidad ${ }^{13}$. En ocasiones, se ha definido la inclusión digital como una política ${ }^{14}$, o un conjunto de políticas ${ }^{15}$ que nacen del reconocimiento de la importancia de las TIC en la sociedad, lo que a su vez reclama una acción del Estado para que los individuos puedan acceder a ellas. La brecha digital, que crea una menesterosidad social, reclama una acción estatal para garantizar un acceso efectivo a un bien vital en la actualidad como las TIC. A pesar de su importancia, no están claros los parámetros que definen que una comunidad o individuo están incluidos digitalmente ${ }^{16}$. Aunque es claro que la inclusión digital solo es posible cuando hay una infraestructura (redes e instalaciones), las condiciones para ser incluido digitalmente sobrepasan la estructura física. La verdadera inclusión demanda recurso humano cualificado, tanto en la prestación

11 Organización de las Naciones Unidas para la Educación, la Ciencia y la Cultura, UNESCO, Hacia las sociedades del conocimiento (Publicaciones UNESCO, París, 2005). Disponible en: http:// unesdoc.unesco.org/images/0014/001419/141908s.pdf

$12 \mathrm{Al}$ respecto, puede consultarse la formulación del sistema-mundo de Immanuel Wallerstein, que clasifica los países en centrales, semiperiféricos y periféricos según su nivel de dominación. IMmanuel Maurice Wallerstein, Análisis de sistemas-mundo: una introducción, 40 (CARlos Daniel Schroeder, trad., Siglo XXI, México, 2006).

13 María del Carmen Agustín-Lacruz \& Manuel Clavero-Galofré, Indicadores sociales de inclusión digital: brecha y participación ciudadana, en Derecho, gobernanza y tecnologías de la información en la sociedad del conocimiento, 143-166 (Prensas Universitarias de Zaragoza, Zaragoza, 2010). Disponible en: http://eprints.rclis.org/14264/1/Indicadores_brecha.pdf

14 Para Fernanda Ribeiro, "es un término utilizado para adjetivar diferentes acciones, programas y políticas públicas relacionadas con las TIC”. FERnANDA RIBEIRO-Rosa, Inclusión digital como política pública: disputas en el campo de los derechos humanos, 18 Revista Sur, 33-55 (2013). Disponible en: http://www.corteidh.or.cr/tablas/r32486-1.pdf

15 Para Scott S. Robinson, se trata de un "conjunto de políticas públicas relacionadas con la construcción, administración, expansión, ofrecimiento de contenidos y desarrollo de capacidades locales en las redes digitales públicas, alámbricas e inalámbricas, en cada país y en la región entera. Incluye las garantías de privacidad y seguridad ejercidas de manera equitativa para todos los ciudadanos". Scott S. Robinson, Reflexiones sobre la inclusión digital, 195 Nueva Sociedad, 126-140, 127 (2005). Disponible en: http://nuso.org/media/articles/downloads/3244_1.pdf

16 Fernanda Ribeiro-Rosa, Inclusión digital como politica pública: disputas en el campo de los derechos humanos, 18 Revista Sur, 33-55 (2013). Disponible en: http://www.corteidh.or.cr/tablas/ r32486-1.pdf 
del servicio como en el uso ${ }^{17}$. Por ese motivo, se considera que un individuo está incluido digitalmente si tiene acceso de calidad a los servicios TIC.

Ahora bien, Cristina Kiomi Mori identifica tres aristas en la comprensión del concepto de inclusión digital: acceso, alfabetización digital y apropiación de tecnologías. La primera requiere una distribución de bienes y servicios que garanticen el acceso a la infraestructura TIC. La segunda se fundamenta en las habilidades básicas que permiten al individuo hacer uso de las TIC, lo que a su vez exige alfabetización escolar. La tercera implica que los individuos dejen de ser meros consumidores y desarrollen una comprensión de las TIC que les permita apropiarse de ellas ${ }^{18}$. En el ámbito público, la inclusión digital dejó de ser una propuesta novedosa y pasó a ocupar un espacio obligatorio en las políticas públicas, debido al enorme potencial para mejorar la calidad de vida y la competitividad de las naciones.

\section{II. ¿NUEVOS DERECHOS, NUEVAS GENERACIONES?}

Debido a la multiplicidad de términos y disputas verbales con respecto a la denominación de los derechos - debate que no se dará a profundidad en este escenario-, se toma en consideración el contexto de la sociedad de la información, que supone necesariamente hablar de derechos humanos, al observar la tecnología como motor de la calidad de vida ${ }^{19}$. En ese entendido, abordaremos en primer lugar los derechos humanos como "aquellos donde se recoge ciertos elementos de moralidad que, debiéndose trasladar al derecho positivo, aún no han sido juridificados"20.

17 Michel J. Menou, La alfabetización informacional dentro de las políticas nacionales sobre tecnologías de la información y comunicación (TICs): la cultura de la información, una dimensión ausente, 7 Anales de Documentación, 241-261 (2004). Disponible en: http://revistas.um.es/analesdoc/article/ view/3771/3671

18 Cristina KIOMI Mori, Politicas públicas para inclusão digital no Brasil: aspectos institucionais e efetividade em iniciativas federais de disseminação de telecentros no periodo 2000-2010, (2011). Disponible en: http://repositorio.unb.br/bitstream/10482/10560/1/2011_CristinaKiomiMori

19 Javier Bustamante-Donas, Los nuevos derechos humanos: gobierno electrónico e informática comunitaria,4Enl@ce, 2, 13-27 (2007). Disponible en: http://www.produccioncientifica.luz.edu. ve/index.php/enlace/article/view/13379/13364

20 María Eugenia Rodríguez-Palop, Claves para entender los nuevos derechos humanos, 23 (Libros de la Catarata, Madrid, 2011). Además, Antonio Enrique Pérez-Luño ofrece un concepto de dere- 
Algunas teorías de los derechos propenden por la redefinición de los catálogos de los derechos y hacen caso omiso a su jerarquización, ya que el hombre es capaz de modificar su entorno y su historia para crear cada vez nuevas condiciones de vida y que por lo tanto hacen necesaria su consagración como derechos; de otra manera, el ser humano no podría ver realizada su existencia dentro de los parámetros propios de la dignidad humana si no se le garantizan los derechos que surgen del desarrollo de su entorno ${ }^{21}$. Un caso contrario sucede con la existencia de teorías de los derechos humanos que apuntan a la conformación de catálogos rígidos de derechos que impiden que nuevos derechos surgidos del contexto histórico, político o social sean considerados como derechos fundamentales ${ }^{22}$.

Los derechos fundamentales están condicionados a factores extrajurídicos de carácter social, económico o cultural que favorecen, dificultan o impiden su efectividad ${ }^{23}$. La posibilidad de aceptar nuevas necesidades históricas que impliquen el surgimiento de nuevos derechos o en otros casos se adapten los existentes a nuevas condiciones $^{24}$, permitiría que la inclusión digital sea considerada como un nuevo derecho en concordancia con lo señalado por Norberto Bobbio, que considera los derechos humanos como una clase variable, evidencia de la historia de la humanidad, cuyo catálogo de derechos se ha modificado y continúa haciéndolo con el cambio de las necesidades, intereses, clases en el poder, las transformaciones técnicas, etc. ${ }^{25}$. Ciertamente, los derechos humanos tienen inmersos

chos humanos que considera este problema al señalar que se trata de un "conjunto de facultades e instituciones que, en cada momento histórico, concretan las exigencias de la dignidad y la igualdad humanas, las cuales deben ser reconocidas positivamente por los ordenamientos jurídicos a nivel nacional e internacional". Antonio EnRiQue PÉREZ-Luño, Delimitación conceptual de los derechos humanos, en Los derechos humanos: significación, estatuto jurídico y sistema, 13-46 (ANTONIO EnriQue PÉrez-LuÑo, coord., Secretariado de Publicaciones de Universidad de Sevilla, Sevilla, 1979).

21 Jorge CARPIZo, Los derechos humanos: naturaleza, denominación y características, 25 Cuestiones Constitucionales, Revista Mexicana de Derecho Constitucional, 3-29 (2011). Disponible en: https:// revistas.juridicas.unam.mx/index.php/cuestiones-constitucionales/article/view/5965/7906

22 Karel VASAK, Las dimensiones internacionales de los derechos humanos (Serbal-UNESCO, Barcelona, 1984). Para profundizar en el tema pueden leerse autores como MARía EugENIA RodríguezPALOP, Claves para entender los nuevos derechos humanos, 44-45 (Libros de la Catarata, Madrid, 2011).

23 Állvaro Andrés Motta-Navas, Hacia la determinación del contenido esencial de los derechos fundamentales, 110 Vniversitas, 519-542 (2005). Disponible en: http://revistas.javeriana.edu.co/ index.php/vnijuri/article/view/14696/11852

24 Antonio Enrique Pérez-Luño, Concepto y concepción de los derechos humanos (acotaciones a la ponencia de Francisco Laporta), 4 Doxa: Cuadernos de Filosofía del Derecho, 6, 47-66 (1987). Disponible en: https://rua.ua.es/dspace/bitstream/10045/10898/1/Doxa4_02.pdf

25 Bobbio rechaza, además, que estos derechos sean reconocidos así por naturaleza propia; en cambio, 
los derechos fundamentales que han sido los que han alcanzado rango de derecho positivo y suelen identificarse a su vez como derechos constitucionales entendidos como "exigencias que han sido recibidas por las normas constitucionales y, que en mayor parte de los casos, se estructuran como derechos subjetivos" 26 . Tal como lo refiere Gregorio Peces-Barba, resulta conveniente apropiarse de la calificación "derechos fundamentales" como la pretensión moral justificada y su recepción en el Derecho positivo ${ }^{27}$. En este entendido, "la justificación de la pretensión moral en que consisten los derechos se produce sobre rasgos importantes derivados de la idea de dignidad humana, necesarios para el desarrollo integral del ser humano. La recepción en el derecho positivo es la condición para que pueda realizar eficazmente su finalidad" 28 .

Robert Alexy, por su parte, argumenta que hay teorías históricas que explican el surgimiento de los derechos fundamentales (ejemplo de ello las expuestas por Hans Kelsen y Carl Schmitt), teorías filosóficas que se ocupan de su fundamentación (John Rawls y Robert Nozick) ${ }^{29}$ y teorías sociológicas que se ocupan de determinar la función en el sistema social de los derechos fundamentales (Niklas Luhmann) ${ }^{30}$. Según Alexy, "los derechos fundamentales son principios y los principios son mandatos de optimización y

propone que la consideración de este carácter especial a favor de un derecho depende de la situación espacial y temporal. Norberto BobBio, El tiempo de los derechos, 57, 99 (Editorial Sistema, Madrid, 1991).

26 Norberto Bobbio, El tiempo de los derechos, 24-25 (Editorial Sistema, Madrid, 1991).

27 Gregorio Peces-Barba, Lecciones de derechos fundamentales, 29 (Editorial Dykinson, Madrid, 2004).

28 Al abordar la conceptualización y las teorías de los derechos fundamentales, es posible consultar: Robert Alexy, Teoría de los derechos fundamentales (Centro de Estudios Constitucionales, Madrid, 1993). María del Carmen Barranco-Avilés, La teoría jurídica de los derechos fundamentales (Dykinson, Madrid, 2000). ERnst-WolfGANG BöCKENFÖRdE, Escritos sobre derechos fundamentales (Juan Luis Requejo-Pagés \& Ignacio Villaverde-MenÉndez, trads., 1, Nomos Verlagsgesellschaft, Baden-Baden, 1993). RAFAel F. DE Asís-RoIG, Sobre el concepto y el fundamento de los derechos: una aproximación dualista (Dykinson, Madrid, 2001). Luigi FerRajoli, Derechos y garantías. La ley del más débil (Perfecto Andrés IbáÑez \& Andrea Greppi, trads., Trotta, Madrid, 1995). Hans Kelsen, Teoría pura del derecho (Albert Calsamiglia, trad., Ariel, Barcelona, 1982). Immanuel Kant, La metafísica de las costumbres (Adela Cortina-Orts \& Jesús Conill-SAncho, trads., Tecnos, Madrid, 1977). JAVIER JIMÉNEZ-CAMPO, Derechos fundamentales: concepto y garantías (Trotta, Madrid, 1999). Jürgen Habermas, Facticidad y validez. Sobre el derecho y el Estado democrático de derecho en términos de teoría del discurso (MAnuel Jiménez-Redondo, trad., Trotta, Madrid, 1998).

29 John Rawls, Theory of Justice (Harvard University Press, Cambridge, Massachusetts, 1971). ROBERT Nozick, Anarchy, State and Utopia (Cornell University Press, Ithaca, New York, 1974).

30 Robert Alexy, Teoría de los derechos fundamentales, 27 (Centro de Estudios Constitucionales, Madrid, 1993). Niklas Luhmann, Grundrechte als Institution (Duncker \& Humblot, Berlin, 1974). 
para protegerlos y garantizarlos, las potestades que tiene el juez para interpretar las normas que giran alrededor de los derechos fundamentales son amplias, ya que los catálogos de derechos se nutren de nuevos 'principios' que deben ser considerados cuando de derechos humanos se trata" ${ }^{31}$. Por lo argumentado, Alexy nos da una alternativa si queremos considerar la inclusión digital como nuevo derecho siendo necesaria la redefinición de los nuevos catálogos de derechos fundamentales ${ }^{32}$.

En ese sentido, el Estado debe proveer acciones necesarias para proteger y garantizar los nuevos derechos que entrarán a ser parte del cúmulo de derechos fundamentales. Un ejemplo de la potestad del juez se puede apreciar en el caso Grootboom vs. Sudáfrica, en el cual el catálogo de derechos fundamentales estaba conformado por los derechos civiles y políticos consagrados en su carta constitucional, pero dejaba aparentemente rezagados los derechos económicos, sociales y culturales. La Corte Constitucional sudafricana argumentó que el Estado está obligado a llevar a cabo acciones positivas para satisfacer las necesidades de las personas y que el juez hace una interpretación integral de los derechos sin entrar en jerarquizaciones de ellos; por el contrario, se deben complementar los considerados derechos civiles y políticos con los derechos económicos, sociales y culturales ${ }^{33}$.

31 Robert Alexy, Teoria de los derechos fundamentales (Centro de Estudios Constitucionales, Madrid, 1993). Además, puede consultarse el análisis de Carlos Bernal-Pulido. Carlos Bernal-Pulido, El carácter fundamental de los derechos fundamentales, en Derechos fundamentales, principios $y$ argumentación. Estudios sobre la teoría jurídica de Robert Alexy, 91-110 (LAURA CLÉRICO, JAN-R. Sieckmann, Ángel Daniel Oliver-Lalana, coords., Comares, Granada, 2011).

32 Robert Alexy, Teoría de los derechos fundamentales (Centro de Estudios Constitucionales, Madrid, 1993).

33 Sudáfrica, Corte Constitucional, South Africa and others v. Irene Grootboom and others, CCT 11/00 [2000] ZACC 19, Sentencia de 21 de septiembre de 2000. Disponible en: http://www.saflii.org/za/ cases/ZACC/2000/19.pdf. Sudáfrica, Corte Constitucional, Irene Grootboom and others v. South Africa and others, CCT 38/00 [2000] ZACC 14, Sentencia de 21 de septiembre de 2000. Disponible en: http://www.saflii.org/za/cases/ZACC/2000/14.html. Al respecto, también pueden consultarse los fallos de la Corte Constitucional sudafricana: Sudáfrica, Corte Constitucional, Soobramoney v. Minister of Health (Kwazulu-Natal), CCT32/97 [1997] ZACC 17, Sentencia de 27 de noviembre de 1997. Disponible en: http://www.saflii.org/za/cases/ZACC/1997/17.html. Sudáfrica, Corte Constitucional, South Africa and others v. Irene Grootboom and others, CCT 11/00 [2000] ZACC 19, Sentencia de 21 de septiembre de 2000. Disponible en: http://www.saflii.org/za/cases/ZACC/2000/19. pdf. Sudáfrica, Corte Constitucional, Irene Grootboom and others v. South Africa and others, CCT 38/00 [2000] ZACC 14, Sentencia de 21 de septiembre de 2000. Disponible en: http://www.saflii. org/za/cases/ZACC/2000/14.html. Sudáfrica, Corte Constitucional, Minister of Health and others v. Treatment Action Campaign and others, CCT9/02 [2002] ZACC 16, Sentencia de 5 de julio de 2002. Disponible en: http://www.saflii.org/za/cases/ZACC/2002/16.pdf 
No obstante, autores como Javier Jiménez-Campo se oponen a considerar los derechos fundamentales como principios, por su indeterminación conceptual de los mismos y por las potestades aparentemente ilimitadas de los jueces para interpretar las normas constitucionales que tienen inmersos derechos fundamentales ${ }^{34}$. En ese sentido, Juan Antonio García-Amado refiere que "las apreciaciones subjetivas del juez constituirían la balanza con la que se pondera", lo cual no permite ofrecer una única respuesta correcta para los casos en que se aplica" ${ }^{35}$. Ernst-Wolfgang Böckenförde también comparte esta idea y menciona que "el control de decisiones judiciales sería inexistente cuando se ponderan derechos fundamentales y principios porque la decisión se basaría exclusivamente en las apreciaciones del juez por lo cual no existirían criterios jurídicos que garanticen la objetividad"36. Así mismo, Manuel García-Pelayo considera que "la Constitución no está formada por una resultante de entornos parciales que nacen de los acontecimientos novedosos, sino que se debe instaurar una estructura organizacional estatal en la que se enmarquen todos los casos particulares" ${ }^{37}$.

Sin embargo, Luigi Ferrajoli se suma a lo argumentado por Alexy al referir que el progreso de la democracia constitucional se mide precisamente por la expansión de los derechos y de su accionabilidad, de tal suerte que sucede una simbiosis en la cual la democracia se nutre de la existencia de derechos y garantías que exigen la ampliación del Estado y la participación de los individuos en las esferas de poder, pero a su vez la democracia está al servicio de estos derechos al garantizar su tutela ${ }^{38}$.

La posibilidad de extender esta lista de derechos es cada vez más pertinente. Es innegable que las TIC han generado un sinnúmero de transformaciones sociales que han modificado las condiciones de existencia, con lo cual el individuo requiere la garantía de nuevas

34 JAVIER JimÉnEZ-CAMPo, Derechos fundamentales: concepto y garantías (Trotta, Madrid, 1999).

35 Juan Antonio García-Amado, Derechos y pretextos. Elementos de crítica del neoconstitucionalismo, en Teoría del neoconstitucionalismo: ensayos escogidos, 237-264 (Miguel CARBonell-SÁnChez, coord., Trotta, Valencia, 2007). Además, se puede consultar la crítica de Carlos Bernal-Pulido a la proporcionalidad en: http://diccionario.pradpi.org/inicio/index.php/terminos_pub/to_pdf/114

36 ERnst-Wolfgang Böckenförde, Escritos sobre derechos fundamentales (JuAn Luis Requejo-Pagés \& Ignacio Villaverde-MenÉndeZ, trads., 1, Nomos Verlagsgesellschaft, Baden-Baden, 1993).

37 Manuel García-Pelayo, Derecho constitucional comparado (Universidad de Murcia, Murcia, 1950).

38 Gerardo A. Durango-Álvarez, Aproximaciones conceptuales a la democracia constitucional y a los derechos fundamentales en la Teoría de L. Ferrajoli, 6 Opinión Jurídica, 12, 189-204 (2007). 
prerrogativas para vivir dignamente. En este sentido, Pedro LópezLópez y Toni Samek, ${ }^{39}$ siguiendo a Yolanda Sánchez-Gómez, señalan que dentro de la denominada tercera generación de derechos aparecen aquellos que provienen de las transformaciones tecnológicas, de los nuevos conocimientos científicos y de su aplicación a diversos campos de la vida humana ${ }^{40}$. Javier Bustamante-Donas habla de una cuarta generación que nace de una nueva comprensión de los derechos humanos a raíz de la relación entre los desarrollos técnicos y el entorno humano ${ }^{41}$. Para Alix Aguirre-Andrade y Nelly Manasía-Fernández ${ }^{42}$, la reformulación de los derechos humanos a partir de la aplicación de las tecnologías y el beneficio comunitario derivado del uso de ellas ha producido el estudio de una cuarta generación de derechos humanos. Pérez-Luño ${ }^{43}$ señala que los derechos relacionados con las nuevas TIC hacen parte de los derechos de la tercera generación que aparecen y complementan la fase anterior de derechos individuales y sociales, los cuales surgen a raíz de la redimensión que estas tecnologías han generado en las relaciones humanas ${ }^{44}$.

Así observamos que países en Suramérica ya han concebido la inclusión digital como un nuevo derecho. Por ejemplo, la Constitución Política de Ecuador garantiza el acceso universal de los ciudadanos a las $\mathrm{TIC}^{45}$, así como otros derechos subsiguientes que

39 Pedro López-López \& Toni SAmek, Inclusión digital: un nuevo derecho humano, 21 Educación y Biblioteca, 172, 114-118 (2009). Disponible en: http://eprints.ucm.es/11567/1/INCLUSION_ DIGITAL\%2C_NUEVO_DERECHO_H.pdf

40 Javier Bustamante-Donas, La cuarta generación de derechos humanos en las redes digitales, 85 Revista Telos, 1-10 (2010). Disponible en: https://telos.fundaciontelefonica.com/url-direct/pdf-gen erator?tipoContenido $=$ articuloTelos \&idContenido $=2010110411480001 \&$ idioma $=$ es

41 Javier Bustamante-Donas, La cuarta generación de derechos humanos en las redes digitales, 85 Revista Telos, 1-10 (2010).

42 Alix Aguirre-Andrade \& Nelly Manasía-Fernández, Derechos humanos de cuarta generación: inclusión social y democratización del conocimiento, 14 Télématique: Revista Electrónica de Estudios Telemáticos, 1, 2-16 (2014). Disponible en: http://publicaciones.urbe.edu/index.php/telematique/ article/view/3483/pdf

43 Antonio Enrique Pérez-Luño, Concepto y concepción de los derechos humanos (acotaciones a la ponencia de Francisco Laporta), 4 Doxa: Cuadernos de Filosofía del Derecho, 6, 47-66 (1987). Disponible en: https://rua.ua.es/dspace/bitstream/10045/10898/1/Doxa4_02.pdf

44 Pedro LóPez-LóPez \& Toni SAMEK, Inclusión digital: un nuevo derecho humano, 21 Educación y Biblioteca, 172, 114-118 (2009). Disponible en: http://eprints.ucm.es/11567/1/INCLUSION DIGITAL\%2C_NUEVO_DERECHO_H.pdf

45 El artículo 16 numeral 2 de la Constitución Política reza: “Todas las personas, en forma individual o colectiva, tienen derecho a: 2 . El acceso universal a las tecnologías de información y comunicación”. Ecuador, Decreto Legislativo 0, Constitución Política de 2008, 449 Registro Oficial, 20 de octubre de 2008. Disponible en: http://www.oas.org/juridico/pdfs/mesicic4_ecu_const.pdf. En el Título Segundo sobre derechos, aparece la Sección Tercera titulada Comunicación e información 
permiten observar el reconocimiento de derechos y condiciones básicas para que los individuos estén incluidos digitalmente. Costa Rica declaró, mediante sentencia de 2010, de la Sala Constitucional de la Corte Suprema de Justicia, que el acceso a internet y en general a las telecomunicaciones, debe ser garantizado a la universalidad de la población tanto por entidades públicas como privadas para no vulnerar el derecho fundamental a la información y la comunicación. En la sentencia, se reconoce el derecho de comunicación e información como un derecho fundamental, distinto al de libertad de expresión, y se plantea que este nuevo derecho genera una obligación positiva en cabeza del Estado y de los particulares encargados por é ${ }^{46}$. Por su parte, Francia protegió desde 2009 mediante jurisprudencia del Consejo Constitucional, el derecho de libertad de acceso a los servicios de comunicación, pero no como un derecho independiente sino como parte del derecho fundamental a la libertad de expresión de pensamientos y opiniones. Aquí se consideraron el desarrollo y el estado actual de los medios de comunicación y los servicios de comunicación al público en línea, y su creciente importancia para la participación en la vida democrática y la expresión de ideas y opiniones ${ }^{47}$.

Por ende, el reconocimiento de la inclusión digital como nuevo derecho es, sin duda alguna, un progreso jurídico en el campo de los derechos humanos que facilita su publicidad y valoración por parte de la sociedad y el Estado. Aunque el derecho comparado y la doctrina arrojan razones para considerar el derecho de la inclusión digital como un nuevo derecho, aún dentro de nuestro sistema jurídico, no se ha positivizado ni se ha reconocido por vía jurisprudencial su carácter de fundamental.

que enlista una serie de derechos relacionados con inclusión digital: http://www.cancilleria.gob.ec/ wp-content/uploads/downloads/2013/02/constitucion_mreci.pdf

46 Costa Rica, Corte Suprema de Justicia, Sala Constitucional, Sentencia 10627-10, 18 de junio de 2010. Disponible en: http://jurisprudencia.poder-judicial.go.cr/SCIJ_PJ/busqueda/jurisprudencia/ jur_Documento.aspx?param1=Ficha_Sentencia\&nValor1=1\&nValor $\overline{2}=483875 \&$ strTipM $=$ T\&strDi rSel=directo

47 Francia, Consejo Constitucional, Decisión 2009-580, 10 de junio de 2009. Disponible en: http:// www.conseil-constitutionnel.fr/decision/2009/2009-580-dc/decision-n-2009-580-dc-du-10juin-2009.42666.html, http:/www.conseil-constitutionnel.fr/conseil-constitutionnel/root/bank_mm/ espagnol/es2009_580dc.pdf 


\section{UNA APROXIMACIÓN COMO DERECHO FUNDAMENTAL DE LA INCLUSIÓN DIGITAL EN COLOMBIA}

Las ventajas ofrecidas por las TIC para todos los sectores han logrado visibilizar las nuevas tecnologías, como mecanismos para el acceso e intercambio de información, saberes, opiniones, entre personas separadas incluso por distancias enormes ${ }^{48}$. En esta realidad, aquellos no incluidos digitalmente están excluidos socialmente, y esta exclusión es una injusticia social ${ }^{49}$. En este sentido, la Organización de Naciones Unidas, ONU, desde años atrás ha insistido en la necesidad de reconocer el acceso a las TIC como una necesidad que requiere atención por parte del Estado. Este órgano se refiere a internet como un vehículo que permite a los ciudadanos el ejercicio y la promoción de los derechos humanos, la participación democrática, la transparencia y el desarrollo económico, por lo cual invita a los Estados a garantizar el acceso a internet para $\operatorname{todos}^{50}$. Posteriormente, de forma directa, la organización solicitó a los Estados promover el acceso a internet ${ }^{51}$.

Por ello, en Colombia, la Ley 1341 de $2009^{52}$, en su artículo 2 numeral 7, consagra el derecho a la comunicación, la información y la educación y los servicios básicos de las TIC e indica que el Es-

48 Alix Aguirre-Andrade \& Nelly Manasía-Fernández, Derechos humanos de cuarta generación: inclusión social y democratización del conocimiento, 14 Télématique: Revista Electrónica de Estudios Telemáticos, 1, 2-16 (2014). Disponible en: http://publicaciones.urbe.edu/index.php/telematique/ article/view/3483/pdf

49 JaVier Bustamante-Donas, Los nuevos derechos humanos: gobierno electrónico e informática comunitaria, 4 Enl@ce, 2, 13-27 (2007). Disponible en: http://www.produccioncientifica.luz.edu. ve/index.php/enlace/article/view/13379/13364

50 FRANK LA RUE, Informe del Relator Especial sobre la promoción y la protección del derecho a la libertad de opinión y de expresión. Nota del secretario general Frank La Rue en el sexagésimo sexto periodo de sesiones, tema 69 (2011). Disponible en: http://www.palermo.edu/cele/pdf/onuinforme-2011-esp.pdf

51 La ONU "exhorta a los Estados a que promuevan y faciliten el acceso a internet y la cooperación internacional encaminada al desarrollo de los medios de comunicación y los servicios de información y comunicación en todos los países", lo cual ha sido interpretado como el reconocimiento de internet como derecho humano por parte del organismo internacional. Naciones Unidas, Consejo de Derechos Humanos, Resolución A /HRC/20/L.13 (2012) Disponible en: http://ap.ohchr.org/documents/S/ $\mathrm{HRC} /$ d_res_dec/A_HRC_20_L13.pdf

52 Colombia, Ley $13 \overline{41}$ de 2009 , por la cual se definen principios y conceptos sobre la sociedad de la información y la organización de las Tecnologías de la Información y las Comunicaciones - TIC-, se crea la Agencia Nacional de Espectro y se dictan otras disposiciones, 47.426 Diario Oficial, 30 de julio de 2009. Disponible en: http://www.secretariasenado.gov.co/senado/basedoc/ley_1341_2009. html 
tado propiciará a todo colombiano el derecho al acceso a las TIC básicas, que permitan el ejercicio pleno del derecho a la educación y el acceso al conocimiento, a la ciencia, a la técnica y a los demás bienes y valores de la cultura, entre otros. Adicionalmente, señala que el Estado creará programas para que la población de los estratos menos favorecidos y la población rural tengan acceso y uso de las plataformas de comunicación. De su lectura, se infiere que el Estado reconoce un derecho subjetivo a favor de los colombianos, al señalar una obligación positiva del Estado: propiciar su acceso a las TIC básicas e, incluso, se obliga a establecer políticas de acceso y uso a favor de los menos favorecidos. En estas circunstancias, ¿puede entenderse que la inclusión digital es reconocida como un derecho fundamental en Colombia?

Para dar respuesta a este interrogante, se parte de la inexistencia de norma positiva o jurisprudencia nacional que concretamente le otorgue esta calidad. En este sentido, se debe analizar si este derecho podría ser considerado fundamental mediante la aplicación de criterios diferentes a la consagración expresa como lo permite el artículo 94 de nuestra Constitución Política de $1991^{53}$.

La jurisprudencia constitucional colombiana ha señalado algunos criterios para identificar los derechos fundamentales, al establecer que la consagración positiva es solo uno de ellos y reconoce otros criterios de carácter analítico y fáctico ${ }^{54}$, sobre los cuales realizaremos una disertación para responder este interrogante.

En primer lugar, se aborda como criterio la conexión con otros derechos fundamentales sobre los cuales el alto Tribunal Constitucional colombiano señaló: "Los derechos constitucionales fundamentales no deben ser analizados aisladamente, sino a través de todo el sistema de derechos que tiene como sujeto a la persona" ${ }^{55}$. En este punto, entre los derechos fundamentales debe haber una

53 El artículo 94 CP reza: "La enunciación de los derechos y garantías contenidos en la Constitución y en los convenios internacionales vigentes, no debe entenderse como negación de otros que, siendo inherentes a la persona humana, no figuren expresamente en ellos". Colombia, Constitución Política, versión corregida 116 Gaceta Constitucional, 20 de julio de 1991. Disponible en: http://www. secretariasenado.gov.co/senado/basedoc/constitucion_politica_1991.html

54 Colombia, Corte Constitucional, Sentencia T-406-92, 5 de junio de 1992, magistrado ponente Ciro Angarita-Barón. Disponible en: http://www.corteconstitucional.gov.co/relatoria/1992/t-406-92.htm

55 Colombia, Corte Constitucional, Sentencia T-402-92, 3 de junio de 1992, magistrado ponente Eduardo Cifuentes-Muñoz. Disponible en: http://www.corteconstitucional.gov.co/relatoria/1992/T-402-92. htm 
interconexión de forma que aparezca una unidad de sentido para su reconocimiento ${ }^{56}$. Con base en este criterio, deducimos que si la inclusión digital es proclamada por vía jurisprudencial como un derecho fundamental, debe encontrarse en interdependencia con otros derechos fundamentales, por lo cual es necesario revisar esta relación con algunos de ellos.

Las TIC tienen una cercana relación con el ejercicio de otros derechos constitucionales pero sería interminable abordar su totalidad en este acápite. Sin embargo, abordaremos algunos como la conexión de la inclusión digital con el derecho a la libertad de expresión. El acceso a las TIC, y con él, la posibilidad de acceder y transmitir información por estos medios, contribuye a que el ciudadano pueda formar libremente sus opiniones y confrontarlas con las de otros, lo que permite la concreción del derecho a la libre expresión en su totalidad, tanto en la exteriorización del pensamiento, como en el acceso al conocimiento que favorece su libre expresión ${ }^{57}$. El acceso a las TIC se vuelve condición necesaria para el ejercicio de la libertad de expresión, debido a la potencial y creciente popularidad que han alcanzado como un medio de difusión de ideas ${ }^{58}$. Las TIC no son los únicos medios para ejercer la libertad de expresión; sin embargo, son los más económicos y accesibles para todos. Por ejemplo, en el caso de internet, para hacer llegar un mensaje masivamente no se requiere formación profesional ni tener una licencia. Tener un acceso limitado a las TIC es un obstáculo para la libertad de expresión ${ }^{59}$.

Los derechos políticos tienen una relación con la inclusión digital pues este último derecho es el que genera una disposición de información por medio de las TIC sobre opciones políticas o

56 Antonio Enrique Pérez-Luño, Dogmática de los derechos fundamentales y transformaciones del sistema constitucional, 20 Teoria y Realidad Constitucional, 495-511 (2007). Disponible en: http://espacio.uned.es/fez/eserv/bibliuned:TeoriayRealidadConstitucional2007-13/dogmatica_dchos.pdf

57 Marcela I. BASTERra, Libertad de expresión y acceso a la información en Iberoamérica, 1 Investigación Jurídica, 1 (2016). Disponible en: http://www.unae.edu.py/ojs/index.php/invjuridica/article/ view/1/2

58 Cicilia M. Krohling Peruzzo, Internet e democracia comunicacional: entre os entraves, utopias e o direito á comunicação, en Direitos à comunicação na sociedade da informação, 267-288 (José Marques de Melo \& Luciano Sathler, eds., São Bernardo do Campo, Universidade Metodista de São Paulo, São Paulo, 2005).

59 JaVier Bustamante-Donas, La sociedad de la información. Hacia la cuarta generación de derechos humanos: repensando la condición humana en la sociedad tecnológica, CTS+I: Revista Iberoamericana de Ciencia, Tecnología, Sociedad e Innovación, Organización de Estados Iberoamericanos, 1 (2001). Disponible en: http://www.oei.es/historico/revistactsi/numero1/bustamante.htm 
mecanismos de votación. En el caso del gobierno electrónico, el acceso online a las bases de datos de la administración pública facilita la difusión y búsqueda de información, lo que genera un aumento en la interacción entre ciudadanos y con el Estado, con lo cual contribuye a la formación de concepciones ideológicas y políticas propias del ciudadano ${ }^{60}$. Olga del Río-Sánchez, citando a Richard Labelle ${ }^{61}$, señala que "el acceso a la información — que las TIC facilitan-, ayuda/puede ayudar a la gente a identificar y evaluar oportunidades de crecimiento y desarrollo y a mejorar sus vidas y las de sus familiares y comunidades". En este sentido, el derecho al libre desarrollo de la personalidad, entendido como aquel de formular y construir su propio proyecto de vida, encuentra en las TIC una herramienta que le facilita conocer un abanico de opciones para desarrollarse en los distintos campos de su vida y alcanzar aquellas metas que considere lo llene de plenitud.

Por otro lado, uno de los criterios que toma en cuenta la Corte Constitucional de Colombia para hablar de derechos fundamentales es la importancia del hecho. Para la Corte, no necesariamente se requiere la consagración expresa de un derecho en la Constitución para que este sea considerado fundamental, sino que puede incorporarse mediante las sentencias de los jueces, que para tal fin deben cotejar la realidad con el catálogo positivo de los derechos fundamentales, la filosofía de la Carta Política determinada en los principios y valores fundamentales y, por último, la doctrina del Estado Social de Derecho. En este criterio, la Corte establece que, con base en dos elementos: normas y hechos, el juez puede construir una interpretación razonable, para alcanzar una sociedad más justa, libre y democrática.

Las novedades introducidas por las TIC se caracterizan por haber penetrado una infinidad de campos de la vida humana y generado nuevos procesos y servicios que en el mejor de los casos plantean caminos alternativos, al ofrecer ventajas ostensibles a

60 Carlos Ariel Sánchez-Torres \& ERick Rincón-CÁrdenas, Municipio digital y gobierno electrónico, 107 Vniversitas, 813-847 (2004). Disponible en: http://revistas.javeriana.edu.co/index.php/vnijuri/ article/view/14801/13301

61 Olga del Río-SÁNChez, TIC, derechos humanos y desarrollo: nuevos escenarios de la comunicación social, 38 Anàlisi: Quaderns de Comunicació i Cultura, 55-69 (2009). Disponible en: http://www. raco.cat/index.php/analisi/article/viewFile/142472/194027, citando a RichARD LABELLE, ICT Policy Formulation and e-Strategy Development: A Comprehensive Guidebook (PNUD-APDIP, Nueva Delhi, 2005). 
quienes puedan acceder a ellas sobre quienes por diferentes condiciones no puedan hacer uso de ellas y se ven obligados a mantenerse atados a procesos y servicios antiguos que pueden entorpecer su desarrollo social. En otros casos, los procesos y servicios antiguos desaparecen y las TIC dejan de ser una alternativa, para pasar a ser la única opción, lo que de entrada excluye a quienes no estén incluidos digitalmente. Ante esta realidad, nuestra sociedad estaría lejos de ser justa, libre y democrática si no garantiza el acceso universal y de calidad a las TIC. La coherencia con los principios fundamentales - en este caso, los del Estado Social de Derechorechazan la exclusión digital porque ella impide que Colombia efectivamente sea una república democrática, participativa y pluralista. Por último, la Corte considera el carácter histórico como otro criterio para saber si estamos ante un derecho fundamental. La categoría de derecho fundamental tiene un carácter histórico, lo cual genera dos implicaciones: a) No todos los derechos fundamentales han sido tenidos por tal en todos los tiempos, sino que se adaptan a la evolución de la sociedad civil, y b) La entidad de fundamental de un derecho depende de la visión que la sociedad tiene de estos derechos. La Corte señala que los derechos fundamentales son fruto de su reconocimiento positivo en la Constitución Política; sin embargo, asegura que no son ajenos a su realidad fenomenológica $\mathrm{y}$, por lo tanto, se identifican con la estructura abierta y dinámica de la Carta Magna. Por lo tanto, para su reconocimiento ha de tenerse en cuenta el momento actual en que se analiza el derecho. En nuestro caso, el derecho a la inclusión digital debe apreciarse en el contexto de la sociedad de la información y las sociedades del conocimiento.

En este momento histórico, la inclusión digital ha sido reconocida de forma genérica en el ámbito internacional, incluso con nombres diversos, en un sinnúmero de documentos, sin que se haya plasmado en instrumentos de derecho internacional dotados de coacción jurídica. Este derecho consiste en el acceso a elementos materiales y prestacionales que le permitan al individuo participar en la mentada sociedad de la información. En el derecho a la inclusión digital debe incorporarse, por ejemplo, la consideración de acceso universal a internet y la necesidad de adoptar políticas de 
alfabetización digital ${ }^{62}$. Ahora bien, al haber revisado los criterios para considerar la inclusión digital como un derecho fundamental encontramos otro debate sobre la posibilidad de concebir la inclusión digital como un derecho fundamental conexo, porque se presenta como un posible medio para lograr igualdad, educación y participación política, entre otros derechos ${ }^{63}$. Sin embargo, hay razones para considerar la inclusión digital como un derecho fundamental autónomo.

En este sentido, la Corte ha establecido otros criterios básicos para el reconocimiento de un derecho fundamental autónomo, mediante la sentencia de tutela T-760-08 ${ }^{64}$, en la que, rememorando jurisprudencia anterior, indicó: "son fundamentales (i) aquellos derechos respecto de los cuales existe consenso sobre su naturaleza fundamental y (ii) todo derecho constitucional que funcionalmente esté dirigido a lograr la dignidad humana y sea traducible en un derecho subjetivo" 65 . En este fallo, la Corte retoma criterios de decisiones anteriores y señala que un derecho no consagrado como fundamental taxativamente en el texto constitucional, puede considerarse así 'de manera autónoma', cuando se puede concretar en una garantía subjetiva derivada de las normas que lo regulan ${ }^{66} ; \mathrm{y}$ cuando este tenga una estrecha relación con la dignidad humana, pues esta última es el elemento fundante del estado social de derecho que impone a las autoridades y a los particulares el trato a la persona conforme con su humana condición ${ }^{67}$.

62 Lorenzo Cotino-Hueso, Algunas claves para el análisis constitucional futuro de las libertades públicas ante las nuevas tecnologías (con especial atención al fenómeno de los "Blogs", en Estudios jurídicos sobre la sociedad de la información y nuevas tecnologías con motivo del XX aniversario de la Facultad de Derecho de Burgos, 51-76 (Santiago A. Bello-Paredes \& Alfonso Murillo-Villar, coords., Servicio de Publicaciones, Burgos, 2005).

63 Colombia, Corte Constitucional, Sentencias T-801-98, 16 de diciembre de 1998, magistrado ponente Eduardo Cifuentes-Muñoz. Disponible en: http://www.corteconstitucional.gov.co/ relatoria/1998/t-801-98.htm. Colombia, Corte Constitucional, Sentencia T-227-03, 17 de marzo de 2003, magistrado ponente Eduardo Montealegre-Lynett. Disponible en: http://www.corteconstitucional.gov.co/relatoria/2003/t-227-03.htm

64 Colombia, Corte Constitucional, Sentencia T-760-08, 31 de julio de 2008, magistrado ponente Manuel José Cepeda-Espinosa. Disponible en: http://www.corteconstitucional.gov.co/relatoria/2015/t-760-08. htm

65 Además, puede revisarse: Colombia, Corte Constitucional, Sentencia T-227-03, 17 de marzo de 2003, magistrado ponente Eduardo Montealegre-Lynett. Disponible en: http:/www.corteconstitucional. gov.co/relatoria/2003/t-227-03.htm

66 Colombia, Corte Constitucional, Sentencia T-859-03, 25 de septiembre de 2003, magistrado ponente Eduardo Montealegre-Lynett. Disponible en: http://www.corteconstitucional.gov.co/ relatoria/2003/t-859-03.htm

67 Colombia, Corte Constitucional, Sentencia C-811-07, 3 de octubre de 2007, magistrado po- 
La sociedad de la información y las sociedades del conocimiento en las que vivimos y/o deseamos vivir, permiten el goce pleno y efectivo de la vida humana con todas las ventajas propias de estas sociedades cuando las personas están incluidas digitalmente y logran así la relación con la dignidad humana. Además, se puede concretar como una garantía subjetiva, ya que la Ley 1341 de 2009 consagra el acceso a las TIC como un derecho subjetivo, pues lo radica en cabeza de cada ciudadano e indica que es obligación del Estado garantizarlo no solo mediante la obligación negativa de abstenerse de obstaculizarlo, sino mediante acciones positivas para hacerlo efectivo. Así las cosas, este derecho cumple los requisitos exigidos por la jurisprudencia para considerarse un derecho fundamental autónomo.

\section{ACCIÓN DE TUTELA COMO MECANISMO PARA LA PROTECCIÓN DE LA INCLUSIÓN DIGITAL}

El reconocimiento de un derecho como tal en la doctrina, jurisprudencia o norma positiva no necesariamente va a permitir su efectividad real, si no se garantiza su ejercicio. En esta coyuntura, la proclamación del derecho no basta si se evade el problema real de adoptar las medidas para su efectiva protección.

En el caso de la inclusión digital, el hecho de que sea reconocida como derecho no garantiza su eficacia, porque los derechos humanos son un deber ser que aparecen como un ideal social ${ }^{68}$. En Colombia, el ordenamiento jurídico consagra diferentes mecanismos judiciales para hacer efectivos los derechos subjetivos de las personas; sin embargo, hay unos especiales para derechos fundamentales que los dotan de garantías particulares que facilitan su ejercicio y protección, de allí el interés en que la inclusión digital adquiera la naturaleza de fundamental.

La Constitución Política de Colombia de 1991 define la acción de tutela, en su artículo 86, como un procedimiento preferente y sumario, cuyo objetivo es obtener la protección de derechos fun-

nente Marco Gerardo Monroy-Cabra. Disponible en: http://www.corteconstitucional.gov.co/ relatoria/2007/c-811-07.htm

68 Fernanda Ribeiro-Rosa, Inclusión digital como politica pública: disputas en el campo de los derechos humanos, 18 Revista Sur, 33-55 (2013). Disponible en: http://www.corteidh.or.cr/tablas/ r32486-1.pdf 
damentales mediante una orden judicial inmediata. Debido a su particular eficacia y celeridad, la norma refiere que solo puede ejercerse en aquellos casos en que el individuo no posea otro mecanismo de protección judicial o que existiendo, se busque evitar un perjuicio irremediable.

En el artículo 85 constitucional se enlistan los derechos de protección inmediata, por lo que en un comienzo se interpretaba que exclusivamente esos derechos podían ser protegidos mediante acción de tutela. Sin embargo, la Corte Constitucional de Colombia ha señalado que esta lista no es taxativa y por lo tanto, todo derecho fundamental puede ser protegido mediante acción de tutela ${ }^{69}$. Esta línea jurisprudencial coincide con lo dicho por Luigi Ferrajoli, para quien, en una democracia constitucional, los derechos fundamentales no siempre requieren una norma jurídica que los respalde taxativamente para ser protegidos, pues las normas provenientes de las ramas de poder públicas elegidas democráticamente se encuentran al servicio de las mayorías electoras y en ese sentido, su interés prevalece sobre el de los desprotegidos, de tal forma que se hace necesario que el juez tenga la potestad para aplicar estas normas superiores y garantice el ejercicio de los derechos fundamentales $^{70}$. Una vez demostrado que la inclusión digital, entendida como el derecho subjetivo a acceder y usar las TIC en condiciones de calidad, puede ser considerada como un derecho fundamental, se puede arribar a la conclusión de que aun cuando no esté reconocida taxativamente en ninguna norma positiva como fundamental, se genera en sus titulares la posibilidad de ejercer acción de tutela para reclamar su respeto y efectividad. Hasta 2016, en Colombia no se habían promovido acciones de tutela para conseguir la protección del derecho de la inclusión digital, pues es un tópico de reciente discusión, pero con la difusión de investigaciones como la presente, se espera que los ciudadanos reclamen el respeto de este derecho tanto desde la dimensión negativa (prohibición de perturbación del ejercicio del derecho), como desde la dimensión positiva (acciones tendientes a garantizar el ejercicio del derecho).

69 Colombia, Corte Constitucional, Sentencia T-406-92, 5 de junio de 1992, magistrado ponente Ciro Angarita-Barón. Disponible en: http://www.corteconstitucional.gov.co/relatoria/1992/t-406-92.htm

70 Luigi Ferrajoli, Sobre los derechos fundamentales, 15 Cuestiones Constitucionales, Revista Mexicana de Derecho Constitucional, 113-136 (2006). Disponible en: https://revistas.juridicas.unam.mx/ index.php/cuestiones-constitucionales/article/view/5772/7599 


\section{CONCLUSIONES}

El bienestar individual y colectivo exige en la actualidad que la población tenga acceso universal y de calidad a las TIC, pues ellas han traído ventajas que también aparejan requerimientos que nos llevan a considerar excluidos a aquellos que no están incluidos digitalmente.

Garantizar el derecho a la inclusión digital es ventajoso para cualquier Estado, porque impulsa el desarrollo socioeconómico y cultural. Por ello, no solo merece que se desarrollen políticas públicas para hacerlo realidad entre los asociados, sino además que se consagre positivamente en normas jurídicas o al menos se reconozca jurisprudencialmente, siendo protegido mediante mecanismos de garantía efectivos.

La inclusión digital cumple los criterios exigidos por doctrina y la jurisprudencia constitucional colombiana para ser considerado derecho fundamental, de forma tal que en este momento histórico puede reclamarse no solo su reconocimiento sino también su efectividad, mediante la acción de tutela.

Es prioritario que desde la academia se propicien espacios de discusión sobre la consagración de la inclusión digital como derecho para que empiece a difundirse entre la población el reconocimiento de la necesidad de acceder y usar las TIC en condiciones de universalidad y calidad, con el objetivo de suscitar un movimiento social en pro del ejercicio efectivo de este derecho. 


\section{BIBLIOGRAFÍA}

\section{Libros}

Abendroth, Wolfgang; Forsthoff, Ernst \& Doehring, Karl, El Estado social (Centro de Estudios Constitucionales, Madrid, 1986).

Alexy, Robert, Teoría de los derechos fundamentales (Centro de Estudios Constitucionales, Madrid, 1993).

Ballestero-Díaz, Fernando, La brecha digital. El riesgo de exclusión en la sociedad de la información (Fundación Retevisión, Madrid, 2002).

Barranco-Avilés, María del Carmen, La teoría jurídica de los derechos fundamentales (Dykinson, Madrid, 2000).

Bobbio, Norberto, El tiempo de los derechos (Editorial Sistema, Madrid, 1991).

BÖCKENFÖRde, ERNST-WOLFGANG, Escritos sobre derechos fundamentales (JuAN Luis Requejo-Pagés \& Ignacio Villaverde-Menéndez, trads., 1, Nomos Verlagsgesellschaft, Baden-Baden, 1993).

Castells, Manuel, La galaxia internet (Areté, Madrid, 2001).

Ferrajoli, Luigi, Derechos y garantías. La ley del más débil (Perfecto Andrés Ibáñez \& Andrea GrepPI, trads., Trotta, Madrid, 1995).

Forsthoff, Ernst, El Estado de la sociedad industrial (Instituto de Estudios Políticos, Madrid, 1975). Disponible en: https://www.academia.edu/8664103/ERNST_ FORSTHOFF_EL_ESTADO_SOCIEDAD_INDUSTRIAL

García-Pelayo, Manuel, Derecho constitucional comparado (Universidad de Murcia, Murcia, 1950).

García-Pelayo, Manuel, Las transformaciones del Estado contemporáneo (Alianza, Madrid, 1985).

Habermas, Jürgen, Facticidad y validez. Sobre el derecho y el Estado democrático de derecho en términos de teoría del discurso (MANuel JimÉnez-Redondo, trad., Trotta, Madrid, 1998).

JimÉnez-CAMPo, JAVIER, Derechos fundamentales: concepto y garantías (Trotta, Madrid, 1999).

Kant, Immanuel, La metafísica de las costumbres (Adela Cortina-Orts \& Jesús ConillSANChO, trads., Tecnos, Madrid, 1977).

Kelsen, Hans, Teoría pura del derecho (Albert Calsamiglia, trad., Ariel, Barcelona, 1982).

Luhmann, Niklas, Grundrechte als Institution (Duncker \& Humblot, Berlin, 1974).

Nogueira-Alcalá, Humberto, La interpretación constitucional de los derechos humanos (Ediciones Legales, Lima, 2009).

Nozick, Robert, Anarchy, State and Utopia (Cornell University Press, Ithaca, New York, 1974). 
Norris, PipPa, Digital Divide: Civic Engagement, Information Poverty, and the Internet Worldwide (Cambridge University Press, Cambridge, UK, 2001).

Peces-Barba, Gregorio, Lecciones de derechos fundamentales (Editorial Dykinson, Madrid, 2004).

Rawls, John, Theory of Justice (Harvard University Press, Cambridge, Massachusetts, 1971).

Rodríguez-Palop, María Eugenia, Claves para entender los nuevos derechos humanos (Libros de la Catarata, Madrid, 2011).

Wallerstein, Immanuel Maurice, Análisis de sistemas-mundo: una introducción (CARlos Daniel Schroeder, trad., Siglo XXI, México, 2006).

\section{Colaboración en obras colectivas}

Agustín-Lacruz, María del Carmen \& Clavero-Galofré, Manuel, Indicadores sociales de inclusión digital: brecha y participación ciudadana, en Derecho, gobernanza y tecnologías de la información en la sociedad del conocimiento, 143-166 (Prensas Universitarias de Zaragoza, Zaragoza, 2010). Disponible en: http://eprints.rclis. org/14264/1/Indicadores_brecha.pdf

Bernal-Pulido, Carlos, El carácter fundamental de los derechos fundamentales, en Derechos fundamentales, principios y argumentación. Estudios sobre la teoría jurídica de Robert Alexy, 91-110 (Laura Clérico, Jan-R. Sieckmann, Ángel Daniel Oliver-Lalana, coords., Comares, Granada, 2011).

García-Amado, Juan Antonio, Derechos y pretextos. Elementos de crítica del neoconstitucionalismo, en Teoría del neoconstitucionalismo: ensayos escogidos, 237-264 (Miguel Carbonell-Sánchez, coord., Trotta, Valencia, 2007).

Pérez-Luño, Antonio Enrique, Delimitación conceptual de los derechos humanos, en Los derechos humanos: significación, estatuto jurídico y sistema, 13-46 (ANTONIO Enrique Pérez-Luño, coord., Secretariado de Publicaciones de Universidad de Sevilla, Sevilla, 1979).

Peruzzo, Cicilia M. Krohling, Internet e democracia comunicacional: entre os entraves, utopias e o direito á comunicação, en Direitos à comunicação na sociedade da informação, 267-288 (José Marques de Melo \& Luciano Sathler, eds., São Bernardo do Campo, Universidade Metodista de São Paulo, São Paulo, 2005).

VASAK, KAREL, Las dimensiones internacionales de los derechos humanos (SerbalUNESCO, Barcelona, 1984).

\section{Revistas}

Acevedo, Manuel, Las TIC en las políticas de cooperación al desarrollo: hacia una nueva cooperación en la Sociedad Red, 2 Cuadernos Internacionales de Tecnología para el Desarrollo Humano, 1-10 (2004). Disponible en: http://upcommons.upc.edu/ bitstream/handle/2099/1465/16_Las_TIC.pdf?sequence=1\&isAllowed=y

Aguirre-Andrade, Alix \& Manasía-Fernández, Nelly, Derechos humanos de cuarta 
generación: inclusión social y democratización del conocimiento, 14 Télématique: Revista Electrónica de Estudios Telemáticos, 1, 2-16 (2014). Disponible en: http:// publicaciones.urbe.edu/index.php/telematique/article/view/3483/pdf

Asís-Roig, Rafael F. DE, Sobre el concepto y el fundamento de los derechos: una aproximación dualista (Dykinson, Madrid, 2001).

Basterra, Marcela I., Libertad de expresión y acceso a la información en Iberoamérica, 1 Investigación Jurídica, 1 (2016). Disponible en: http://www.unae.edu.py/ojs/ index.php/invjuridica/article/view/1/2

Bustamante-Donas, Javier, La cuarta generación de derechos humanos en las redes digitales, 85 Revista Telos, 1-10 (2010). Disponible en: https://telos. fundaciontelefonica.com/url-direct/pdf-generator?tipoContenido=articuloTel os\&idContenido $=2010110411480001 \&$ idioma $=$ es

Bustamante-Donas, Javier, La sociedad de la información. Hacia la cuarta generación de derechos humanos: repensando la condición humana en la sociedad tecnológica, CTS+I: Revista Iberoamericana de Ciencia, Tecnología, Sociedad e Innovación, Organización de Estados Iberoamericanos, 1 (2001). Disponible en: http://www. oei.es/historico/revistactsi/numerol/bustamante.htm

Bustamante-Donas, Javier, Los nuevos derechos humanos: gobierno electrónico e informática comunitaria, 4 Enl@ce, 2, 13-27 (2007). Disponible en: http://www. produccioncientifica.luz.edu.ve/index.php/enlace/article/view/13379/13364

CARPIzo, Jorge, Los derechos humanos: naturaleza, denominación y características, 25 Cuestiones Constitucionales, Revista Mexicana de Derecho Constitucional, 3-29 (2011). Disponible en: https://revistas.juridicas.unam.mx/index.php/cuestionesconstitucionales/article/view/5965/7906

Cotino-Hueso, Lorenzo, Algunas claves para el análisis constitucional futuro de las libertades públicas ante las nuevas tecnologías (con especial atención al fenómeno de los "Blogs", en Estudios jurídicos sobre la sociedad de la información y nuevas tecnologías con motivo del XX aniversario de la Facultad de Derecho de Burgos, 51-76 (Santiago A. Bello-Paredes \& Alfonso Murillo-Villar, coords., Servicio de Publicaciones, Burgos, 2005).

Cruz-Villalón, Pedro, Formación y evolución de los derechos fundamentales, 9 Revista Española de Derecho Constitucional, 25, 35-62 (1989). Disponible en: http:// www.cepc.gob.es/publicaciones/revistas/revistaselectronicas?IDR=6\&IDN=3 $27 \& I D A=24923$

Durango-Álvarez, Gerardo A., Aproximaciones conceptuales a la democracia constitucional y a los derechos fundamentales en la Teoría de L. Ferrajoli, 6 Opinión Jurídica, 12, 189-204 (2007).

Fernández-Riquelme, Sergio, La realidad comunitaria de la política social: desafíos teóricos y metodológicos para el trabajo social, 47 Documentos de Trabajo Social: Revista de Trabajo Social y Acción Social, 31-42 (2010). Disponible en: http://www. trabajosocialmalaga.org/archivos/revista_dts_numeros/DTS_47.pdf

Ferrajoli, Luigi, Sobre los derechos fundamentales, 15 Cuestiones Constitucionales, Revista Mexicana de Derecho Constitucional, 113-136 (2006). Disponible en: https://revistas.juridicas.unam.mx/index.php/cuestiones-constitucionales/ article/view/5772/7599 
Laporta-San Miguel, Francisco Javier, Sobre el concepto de derechos humanos, 04 Doxa: Cuadernos de Filosofía del Derecho, 6, 23-46 (1987). Disponible en: https:// rua.ua.es/dspace/bitstream/10045/10897/1/Doxa4_01.pdf

López-López, Pedro \& Samek, Toni, Inclusión digital: un nuevo derecho humano, 21 Educación y Biblioteca, 172, 114-118 (2009). Disponible en: http://eprints.ucm. es/11567/1/INCLUSION_DIGITAL\%2C_NUEVO_DERECHO_H.pdf

Lucchi, Nicola, Access to Network Services and Protection of Constitutional Rights: Recognizing the Essential Role of Internet Access for the Freedom of Expression, 19 Cardozo Journal of International and Comparative Law, 3, 645-678 (2011). Disponible en: https://papers.ssrn.com/sol3/papers.cfm?abstract_id=1756243

Martínez-Coral, PATricia, Intervenciones públicas de inclusión digital: una aproximación a las dimensiones sociales y políticas de la conectividad, 19 Papel Político, 1, 61-76 (2014). Disponible en: http://www.scielo.org.co/pdf/papel/v19n1/v19n1a04.pdf

Menou, Michel J., La alfabetización informacional dentro de las políticas nacionales sobre tecnologías de la información y comunicación (TICs): la cultura de la información, una dimensión ausente, 7 Anales de Documentación, 241-261 (2004). Disponible en: http://revistas.um.es/analesdoc/article/view/3771/3671

Mori, Cristina Kiomi, Políticas públicas para inclusão digital no Brasil: aspectos institucionais e efetividade em iniciativas federais de disseminação de telecentros no período 2000-2010 (2011). Disponible en: http://repositorio.unb.br/ bitstream/10482/10560/1/2011_CristinaKiomiMori

Motta-Navas, Álvaro Andrés, Hacia la determinación del contenido esencial de los derechos fundamentales, 110 Vniversitas, 519-542 (2005). Disponible en: http:// revistas.javeriana.edu.co/index.php/vnijuri/article/view/14696/11852

Pérez-Luño, Antonio Enrique, Concepto y concepción de los derechos humanos (acotaciones a la ponencia de Francisco Laporta), 4 Doxa: Cuadernos de Filosofía del Derecho, 6, 47-66 (1987). Disponible en: https://rua.ua.es/dspace/ bitstream/10045/10898/1/Doxa4_02.pdf

Pérez-Luño, Antonio Enrique, Dogmática de los derechos fundamentales y transformaciones del sistema constitucional, 20 Teoría y Realidad Constitucional, 495-511 (2007). Disponible en: http://e-spacio.uned.es/fez/eserv/bibliuned:Teori ayRealidadConstitucional2007-13/dogmatica_dchos.pdf

Ribeiro-Rosa, Fernanda, Inclusión digital como política pública: disputas en el campo de los derechos humanos, 18 Revista Sur, 33-55 (2013). Disponible en: http://www. corteidh.or.cr/tablas/r32486-1.pdf

Río-Sánchez, Olga del, TIC, derechos humanos y desarrollo: nuevos escenarios de la comunicación social, 38 Anàlisi: Quaderns de Comunicació i Cultura, 55-69, (2009). Disponible en: http://www.raco.cat/index.php/analisi/article/ viewFile/142472/194027

Robinson, Scott S., Reflexiones sobre la inclusión digital, 195 Nueva Sociedad, 126-140 (2005). Disponible en: http://nuso.org/media/articles/downloads/3244_1.pdf

Sánchez-Torres, Carlos Ariel \& Rincón-Cárdenas, Erick, Municipio digital y gobierno electrónico, 107 Vniversitas, 813-847 (2004). Disponible en: http://revistas. javeriana.edu.co/index.php/vnijuri/article/view/14801/13301 
Tole-Martínez, José Julián, La teoría de la doble dimensión de los derechos fundamentales en Colombia. El estado de cosas inconstitucionales, un ejemplo de su aplicación, 16 Cuestiones Constitucionales, Revista Mexicana de Derecho Constitucional, 15, 253-316 (2006). Disponible en: http://www.ejournal.unam.mx/cuc/cconst15/ CUC1510.pdf

\section{Informes, reportes, documentos}

La Rue, Frank, Informe del Relator Especial sobre la promoción y la protección del derecho a la libertad de opinión y de expresión. Nota del secretario general Frank La Rue en el sexagésimo sexto período de sesiones, tema 69 (2011). Disponible en: http://www.palermo.edu/cele/pdf/onu-informe-2011-esp.pdf

Norris, Pippa, The Worldwide Digital Divide: Information Poverty, the Internet and Development, Paper for the Annual Meeting of the Political Studies Association of the UK, London School of Economics and Political Science, 10-13th April 2000, 1-10 (2000). Disponible en: https://pdfs.semanticscholar.org/acff/ d927594b58b81f18ec9f27c64ff9b2ad452e.pdf

\section{Reportes, resoluciones y documentos}

Naciones Unidas, Consejo de Derechos Humanos, Resolución A /HRC/20/L.13 (2012) Disponible en: http://ap.ohchr.org/documents/S/HRC/d_res_dec/A_HRC_20_ L13.pdf.

Organización de las Naciones Unidas para la Educación, la Ciencia y la Cultura, UNESCO, Hacia las sociedades del conocimiento (Publicaciones UNESCO, París, 2005). Disponible en: http://unesdoc.unesco.org/images/0014/001419/141908s.pdf

\section{Normatividad internacional}

Ecuador, Decreto Legislativo 0, Constitución Política de 2008, 449 Registro Oficial, 20 de octubre de 2008. Disponible en: http://www.oas.org/juridico/pdfs/mesicic4_ ecu_const.pdf

\section{Normatividad colombiana}

Colombia, Constitución Política, versión corregida 116 Gaceta Constitucional, 20 de julio de 1991. Disponible en: http://www.secretariasenado.gov.co/senado/basedoc/ constitucion_politica_1991.html

Colombia, Ley 1341 de 2009, por la cual se definen principios y conceptos sobre la sociedad de la información y la organización de las Tecnologías de la Información y las Comunicaciones-TIC-, se crea la Agencia Nacional de Espectro y se dictan otras disposiciones, 47.426 Diario Oficial, 30 de julio de 2009. Disponible en: http://www.secretariasenado.gov.co/senado/basedoc/ley_1341_2009.html 
Colombia, Proyecto de acto legislativo 05 de 2011, por el cual se constituye el acceso a internet como derecho fundamental, se modifica el artículo 20 de la Constitución Política y se dictan otras disposiciones, fecha de radicación 29 de julio de 2011. Disponible en: http://www.congresovisible.org/proyectos-de-ley/por-el-cualse-constituye-el-acceso-a-internet-como-derecho-fundamental-se-modifica-elarticulo-20-de-la-constitucion-politica-y-se-dictan-otras-disposiciones-accesoa-internet-como-derecho-fundamental/6256/\#tab=2

Colombia, Proyecto de acto legislativo 08 de 2014, Senado, por el cual se modifica el artículo 20 de la Constitución Política, se establece el acceso a banda ancha en Internet como derecho fundamental y se dictan otras disposiciones, fecha de radicación 24 de julio de 2014. Disponible en: http://www.imprenta.gov.co/ gacetap/gaceta.mostrar_texto?p_tipo $=03 \&$ p_numero $=08 \&$ p_consec $=39757$

\section{Jurisprudencia internacional}

Costa Rica, Corte Suprema de Justicia, Sala Constitucional, Sentencia 10627-10, 18 de junio de 2010. Disponible en: http://jurisprudencia.poder-judicial.go.cr/SCIJ_PJ/ busqueda/jurisprudencia/jur_Documento.aspx?param1=Ficha_Sentencia\&nVa lorl$=1 \&$ nValor $2=483875 \&$ strTipM=T\&strDirSel=directo

Francia, Consejo Constitucional, Decisión 2009-580, 10 de junio de 2009. Disponible en: http://www.conseil-constitutionnel.fr/decision/2009/2009-580-dc/decision-n2009-580-dc-du-10-juin-2009.42666.html, http://www.conseil-constitutionnel.fr/ conseil-constitutionnel/root/bank_mm/espagnol/es2009_580dc.pdf

Sudáfrica, Corte Constitucional, Minister of Health and Others v. Treatment Action Campaign and others, CCT9/02 [2002] ZACC 16, Sentencia de 5 de julio de 2002. Disponible en: http://www.saflii.org/za/cases/ZACC/2002/16.pdf

Sudáfrica, Corte Constitucional, Soobramoney v. Minister of Health (Kwazulu-Natal), CCT32/97 [1997] ZACC 17, Sentencia de 27 de noviembre de 1997. Disponible en: http://www.saflii.org/za/cases/ZACC/1997/17.html

Sudáfrica, Corte Constitucional, South Africa and others v. Irene Grootboom and others, CCT 11/00 [2000] ZACC 19, Sentencia de 21 de septiembre de 2000. Disponible en: http://www.saflii.org/za/cases/ZACC/2000/19.pdf

Sudáfrica, Corte Constitucional, Irene Grootboom and others v. South Africa and others, CCT 38/00 [2000] ZACC 14, Sentencia de 21 de septiembre de 2000. Disponible en: http://www.saflii.org/za/cases/ZACC/2000/14.html

\section{Jurisprudencia colombiana}

Colombia, Corte Constitucional, Sentencia T-402-92, 3 de junio de 1992, magistrado ponente Eduardo Cifuentes-Muñoz. Disponible en: http://www. corteconstitucional.gov.co/relatoria/1992/T-402-92.htm

Colombia, Corte Constitucional, Sentencia T-406-92, 5 de junio de 1992, magistrado ponente Ciro Angarita-Barón. Disponible en: http://www.corteconstitucional. gov.co/relatoria/1992/t-406-92.htm 
Colombia, Corte Constitucional, Sentencia T-240-93, 23 de junio de 1993, magistrado ponente Eduardo Cifuentes-Muñoz. Disponible en: http://www. corteconstitucional.gov.co/relatoria/1993/t-240-93.htm

Colombia, Corte Constitucional, Sentencias T-801-98, 16 de diciembre de 1998, magistrado ponente Eduardo Cifuentes-Muñoz. Disponible en: http://www. corteconstitucional.gov.co/relatoria/1998/t-801-98.htm

Colombia, Corte Constitucional, Sentencia T-881-02, 17 de octubre de 2002, magistrado ponente Eduardo Montealegre-Lynett. Disponible en: http://www. corteconstitucional.gov.co/relatoria/2002/t-881-02.htm

Colombia, Corte Constitucional, Sentencia T-227-03, 17 de marzo de 2003, magistrado ponente Eduardo Montealegre-Lynett. Disponible en: http://www. corteconstitucional.gov.co/relatoria/2003/t-227-03.htm

Colombia, Corte Constitucional, Sentencia T-859-03, 25 de septiembre de 2003, magistrado ponente Eduardo Montealegre-Lynett. Disponible en: http://www. corteconstitucional.gov.co/relatoria/2003/t-859-03.htm

Colombia, Corte Constitucional, Sentencia C-811-07, 3 de octubre de 2007, magistrado ponente Marco Gerardo Monroy-Cabra. Disponible en: http://www. corteconstitucional.gov.co/relatoria/2007/c-811-07.htm

Colombia, Corte Constitucional, Sentencia T-760-08, 31 de julio de 2008, magistrado ponente Manuel José Cepeda-Espinosa. Disponible en: http://www. corteconstitucional.gov.co/relatoria/2015/t-760-08.htm 